\title{
Sistem Pengaman Sepeda Motor Menggunakan SMS Gateway Berbasis Mikrokontroler ATMega32
}

\author{
Wahyu Ibrahim, Wahyu Sapto Aji \\ Program Studi Teknik Elektro Universitas Ahmad Dahlan Yogyakarta \\ Jln. Prof.Dr. Supomo Yogyakarta. Tlp. (0274)379418, Fax. (0274)381523 \\ e-mail: wahyoe_ibrahim@ymail.com, wahyusaji@gmail.com
}

\begin{abstract}
Abtract
The main purpose of this research wasdevided a motorcycle safety system which is easy used and reliable. The microcontroller ATmega32 is consist proceedof data processor, wavecom M1306B modem interfaced, and Relay Driver Module power supply. The method is used to protect motorcycle early turn off of secreat switch for user and send a message which is writing characters of Motorcycle Danger. Futhermore, the safety system will turn off motorcycle machine, turn on of the horn, and turn on the signlight of motorcycle are made by times automatic. This system work is the wavecom modem active to send a warning message after the motorcycle is started. In the 5 second a safety system will loss the connection of CDI is used to turn off the motorcycle then the 6 second a horn and signlight actived. The result of this research is show the safety system for motorcycle what is made by automatic decission In the conclusion of this research is to safe the motorcycle for user who used catch the thief.
\end{abstract}

Keywords: safety; motorcycle; SMS; microcontroller

\begin{abstract}
Abstrak
Tujuan pembuatan proyek akhir ini adalah mampu mendapatkan suatu sistem pengaman sepeda motor yang mudah digunakan dan dapat dihandalkan. Rancangan alat ini terdiri dari sebuah mikrokontroler ATmega32 sebagai pengolah data, antarmuka modem wavecom M1306B dengan mikrokontroler, Driver Relay dan Modul Power Supply. Prinsip kerja pengaman ini yaitu ketika ada seseorang menghidupkan mesin sepeda motor tanpa men-switch off tombol rahasia terlebih dahulu maka alat ini akan memberikan tanda peringatan kepada pemilik sepeda motor melalui SMS bahwa sepeda motor dalam keadaan bahaya berupa tulisan karakter "Keadaan Motor Bahaya". Setelah alat ini mengirimkan SMS kepada pemilik motor, alat ini kemudian akan mematikan mesin motor, membunyikan klakson dan menyalakan lampu riting secara otomatis berdasarkan pewaktu yang sudah ditentukan. Setelah mesin kendaraan hidup, kemudian modem wavecom akan mengirimkan SMS kepada pemilik sepeda motor. Kemudian pada detik ke-5 sistem pengaman akan memutus jalur $C D I$ sepeda motor yang berakibat sepeda motor akan mati. Pada detik ke-6 klakson dan lampu riting sepeda motor akan aktif. Hasil dari proyek akhir ini menunjukkan sistem pengaman telah bekerja sesuai yang telah diharapkan. Dengan demikian sistem pengaman sepeda motor ini dapat digunakan dengan aman dan mempunyai nilai lebih ketika pemilik sepeda motor berhasil menangkap si pelaku pencurian.
\end{abstract}

Kata Kunci: pengaman; sepeda motor; SMS; mikrokontroler

\section{Pendahuluan}

Semakin kerasnya kehidupan menyebabkan banyak orang menjadi gelap mata. Mereka menghalalkan segala cara untuk memenuhi kebutuhan hidup mereka demi mempertahankan kelangsungan hidupnya, seperti: merampok, korupsi, mencuri, dan tindakan-tindakan kriminal lainnya. Salah satunya tindakan kriminal yang marak di era sekarang adalah tindakan kriminal 
pencurian sepeda motor. Tidak hanya dimalam hari dan di tempat yang sepi saja, di siang hari dan keramaian pun para pencuri dapat melakukkan aksi dengan mudahnya. Maka dibutuhkan kewaspadaan yang lebihuntuk menjaga sepeda motor kita.

\section{Metode Penelitian}

\subsection{Perancangan Sistem Perangkat Keras}

Perancangan perangkat keras terdiri dari sistem kontrol yaitu minimum sistem ATmega32 yang bertugas sebagai pengendali sensor serta melakukan pengolahan data. Perancangan rangkaian-rangkaian sensor serta regulator untuk mensuplai semua perangkat keras yang digunakan dalam penelitian ini. Blok diagram alat pengukuran intensitas cahaya ini dapat dilihat pada Gambar 1.

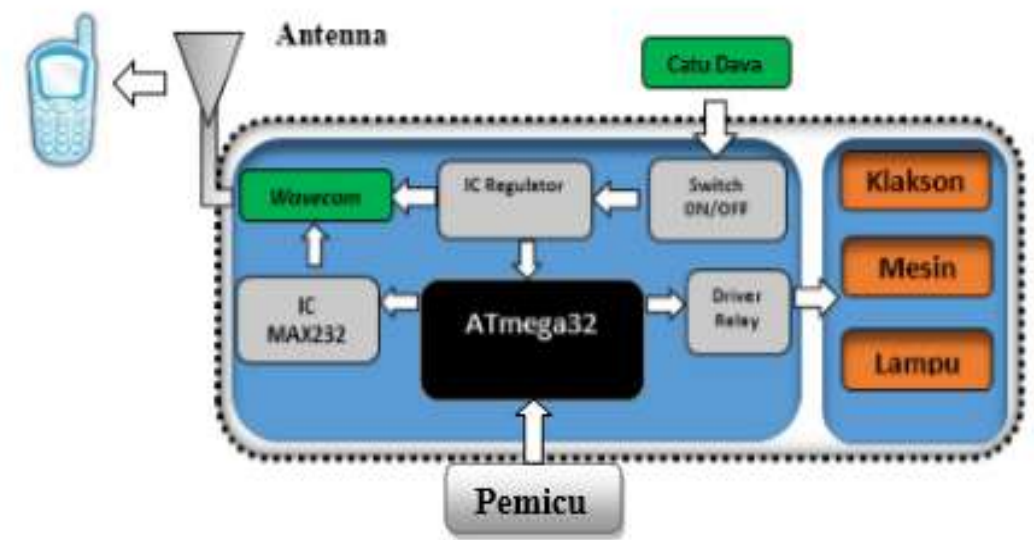

Gambar 1. Blok diagram sistem pengaman sepeda motor menggunakan SMS

\subsubsection{Rangkaian Mikrokontroler ATmega32}

Rangkaian mikrokontroler ATmega32 sebagai pengolah data yang didapat dari pembacaan sensor dari mesin yaitu tegangan. Rangkaian mikrokontroler juga berfungsi sebagai penggabung data yang didapat dari pembacaan sensor menjadi satu kesatuan data agar data dapat disesuaikan dengan perintah yang sudah ditentukan.

\subsubsection{Rangkaian Catu Daya}

Rangkaian catu daya berfungsi sebagai sumber daya bagi rangkaian alat pengatur intensitas cahaya otomatis. Dalam penelitian ini menggunakan catu daya sebesar 12 volt.

\subsubsection{Rangkaian Driver Relay}

Fungsi driver relay untuk mengatur keadaan motor dari kondisi on atau off tanpa adanya campur tangan manusia. Prinsip kerja transistor sebagai saklar adalah dengan memanfaatkan daerah jenuh (saturasi) dan daerah mati (cut off) pada transistor. Ketika transistor pada daerah saturasi maka transistor menjadi saklar tertutup (kolektor > emitor) dan saklar dalam posisi ON. Ketika transistor dalam keadaan saturasi dan transistor seperti saklar tertutup. Jika transistor tersumbat makan transistor menjadi terbuka (cut off) (basis $>$ emitor) dan saklar dalam posisi OFF.

Penelitian tentang pengaruh front time terhadap tegangan residu arester $\mathrm{ZnO}$ dan $\mathrm{SiC}$ akan dilakukan dengan metode pengujian skala laboratorium. Pengujian dilakukan dengan menggunakan peralatan pengujian tegangan tinggi yang terdiri dari beberapa rangkaian yang memiliki fungsi khusus. Secara keseluruhan sistem pengujian pada penelitian ini ditunjukkan pada Gambar 3. Masing-masing blok berisi rangkaian komponen elektronika yang memiliki fungsi tersendiri. Pada sub bab selanjutnya akan dijelaskan fungsi masing-masing blok tersebut dan bahan arester yang digunakan sebagai bahan pengujian pada penelitian ini. 
Jurnal IImu Teknik Elektro Komputer dan Informatika (JITEKI)

Vol. 2, No. 1, Juni 2016

\subsection{Perancangan Perangkat Lunak}

Secara umum perangkat lunak akan menjalankan program untuk mengirimkan SMS, mematikan mesin, menyalakan klakson dan lampu sign.Flowchart perangkat lunak secara umum ditunjukkan pada Gambar 2.

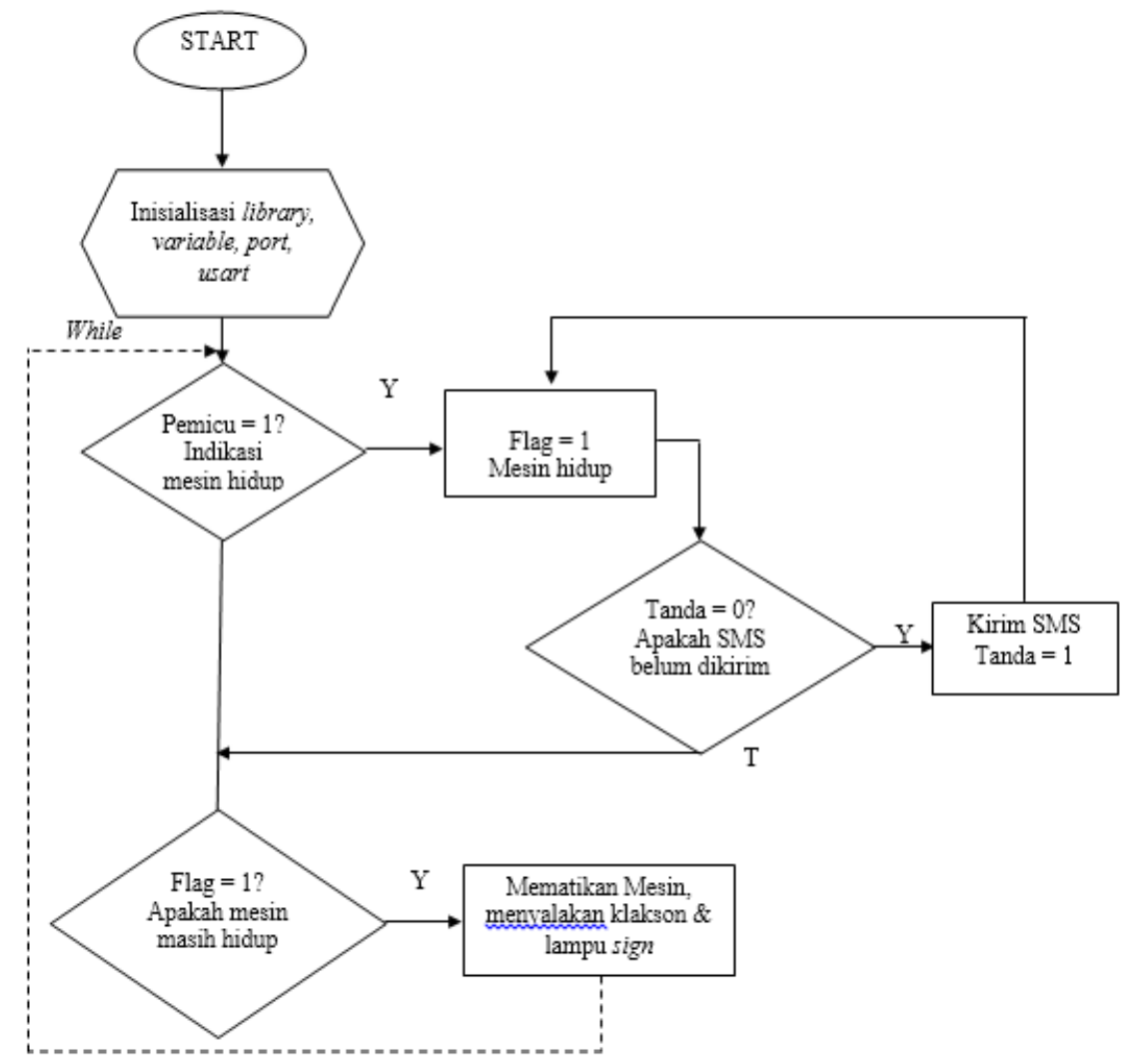

Gambar 2.Diagram alir alat sistem pengaman sepeda motor menggunakan SMS

\subsubsection{Program untuk Mngirimkan SMS}

Perancangan ini merupakan ketika saklar pada alat sistem pengaman sepeda motor sudah aktif dan jika motor dinyalakan tanpa mematikan alat pengaman tersebut, maka alat tersebut akan mengirimkan berupa pesan/SMS "Keadaan Motor Bahaya". Berikut adalah listing program untuk mengirimkan SMS dapat dilihat pada Gambar 3.

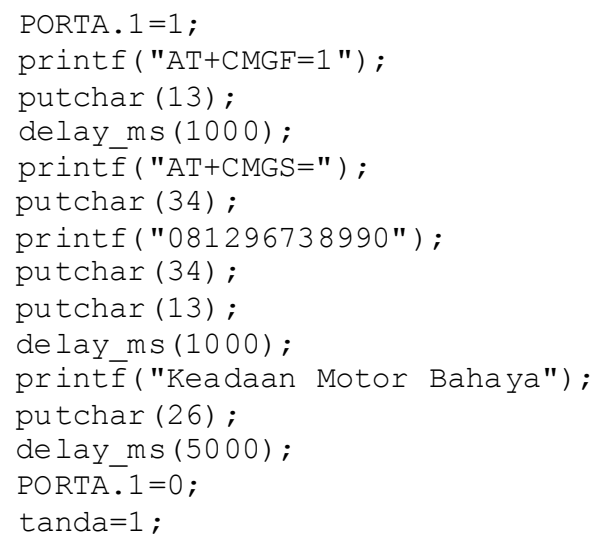

Gambar 3. Program untuk mengirim SMS 
Jurnal IImu Teknik Elektro Komputer dan Informatika (JITEKI)

Vol. 2, No. 1, Juni 2016

\section{Hasil dan Pembahasan}

\subsection{Pengujian Kehandalan Sistem}

Pengujian kehandalan sistem dilakukan untuk mengetahui apakah sistem yang dibuat sudah dapat bekerja dengan baik. Sistem dapat menghasilkan keluaran berupa SMS, mematikan mesin motor, menyalakan klakson dan lampu riting sesuai yang diharapkan. Tabel 1 merupakan hasil dari pengujian kehandalan sistem.

Tabel 1. Hasil pengujian kehandalan sistem

\begin{tabular}{|c|c|c|c|c|c|}
\hline \multirow[b]{2}{*}{ No } & \multirow[b]{2}{*}{ Percobaan } & \multicolumn{4}{|c|}{ Output } \\
\hline & & SMS & Mesin & Klakson & Riting \\
\hline 1 & Percobaan 1 & Terkirim & Mati & Berbunyi & Menyala \\
\hline 2 & Percobaan 2 & Terkirim & Mati & Berbunyi & Menyala \\
\hline 3 & Percobaan 3 & Terkirim & Mati & Berbunyi & Menyala \\
\hline 4 & Percobaan 4 & Terkirim & Mati & Berbunyi & Menyala \\
\hline 5 & Percobaan 5 & Terkirim & Mati & Berbunyi & Menyala \\
\hline 6 & Percobaan 6 & Terkirim & Mati & Berbunyi & Menyala \\
\hline 7 & Percobaan 7 & Terkirim & Mati & Berbunyi & Menyala \\
\hline 8 & Percobaan 8 & Terkirim & Mati & Berbunyi & Menyala \\
\hline 9 & Percobaan 9 & Terkirim & Mati & Berbunyi & Menyala \\
\hline 10 & Percobaan 10 & Terkirim & Mati & Berbunyi & Menyala \\
\hline 11 & Percobaan 11 & Terkirim & Mati & Berbunyi & Menyala \\
\hline 12 & Percobaan 12 & Terkirim & Mati & Berbunyi & Menyala \\
\hline 13 & Percobaan 13 & Terkirim & Mati & Berbunyi & Menyala \\
\hline 14 & Percobaan 14 & Terkirim & Mati & Berbunyi & Menyala \\
\hline 15 & Percobaan 15 & Terkirim & Mati & Berbunyi & Menyala \\
\hline
\end{tabular}

Berdasarkan tabel diatas dapat dilihat dari percobaan 1 sampai 15 sistem pengaman sepeda motor bekerja secara konsisten, walaupun terkadang sms terkirim kepada ponsel pemilik sepeda motor sedikit lebih lama dari percobaan yang dilakukan sebelumnya. Setelah dilakukan beberapa percobaan maka dapat kikatakan alat ini bekerja secara konsisten dan sesuai yang diharapkan.

\subsection{Pengujian Performa Modem Wavecom}

Pengujian ini dilakukan untuk mengetahui jangka waktu yang dibutuhkan sistem pengaman ini untuk mengirimkan SMS sampai ke ponsel pemilik sepeda motor. Perhitungan waktu tempuh dimulai dari perubahan kondisi sensor (mesin hidup) sampai SMS masuk ke Ponsel user dengan sim card Telkomsel dengan nomor (081296738xxx). Pengujian ini dilakukan pada tempat terbuka untuk bertujuan mengetahui berapa waktu yang dibutuhkan 
Jurnal IImu Teknik Elektro Komputer dan Informatika (JITEKI)

Vol. 2, No. 1, Juni 2016

relay untuk aktif, apakah sesuai waktu yang diharapkan. Berikut adalah hasil catatan waktu yang diperoleh dengan menggunakan stopwatch sebagai pencatat waktunya.

Tabel 2. Pengujian performa modem Wavecom

\begin{tabular}{cccc}
\hline No & $\begin{array}{c}\text { Nomor Ponsel Terpasang } \\
\text { pada Modem }\end{array}$ & $\begin{array}{c}\text { Waktu Tempuh SMS } \\
\text { Sampai ke User }\end{array}$ & $\begin{array}{c}\text { Keterangan } \\
\text { (jenis kartu) }\end{array}$ \\
\hline 1 & 08213624 4258 & 8,$4 ; 8,3 ; 8,8=8,6$ detik & Telkomsel \\
\hline 2 & 083840363289 & 8,$1 ; 8,4 ; 8,2=8,2$ detik & Axis \\
\hline 3 & 085878908790 & 9,$4 ; 9,1 ; 8,9=9,1$ detik & Mentari \\
\hline 4 & 087734033518 & 8,$1 ; 8,1 ; 8,2=8,1$ detik & XL \\
\hline 5 & 085741828292 & 9,$2 ; 9,6 ; 9,4=9,4$ detik & IM3
\end{tabular}

\subsection{Pengukuran Delay Relay}

Pada tahapan ini relay akan diuji apakah akan bekerja pada waktu jeda atau delay yang sudah ditentukan. Tabel 3 adalah hasil pengujian dari waktu delay relay.

Tabel 3. Hasil pengujian dari waktu delay relay

\begin{tabular}{cccc}
\hline Proses & Mesin Mati & Klakson Bunyi & Riting Menyala \\
& $($ Relay1 $)$ & $($ Relay2 $)$ & $($ Relay3) \\
\hline Pengamatan 1 & 7 detik & 7 detik & 7 detik \\
\hline Pengamatan 2 & 7 detik & 7 detik & 7 detik \\
\hline Pengamatan 3 & 7 detik & 7 detik & 7 detik \\
\hline Pengamatan 4 & 7 detik & 7 detik & 7 detik \\
\hline Pengamatan 5 & 7 detik & 7 detik & 7 detik \\
\hline
\end{tabular}

Berdasarkan catatan tabel diatas, maka dapat disimpulkan bahwa alat pengaman kendaraan bermotor ini telah bekerja sesuai yang diharapkan.

\section{Kesimpulan}

Setelah mengamati dan membahas sistem pengaman sepeda motor menggunakan SMS Gateway berbasis mikrokontroler ATmega32 ini, sebagai mana telah dijelaskan pada bab-bab sebelumnya maka dapat diambil beberapa kesimpulan yaitu:

1. Alat ini sudah terbukti bisa bekerja secara konsisten dalam mengirimkan SMS kepada pemilik sepeda motor.

2. Relay pada alat ini mampu mematikan mesin, menyalakan klakson dan lampu sign secara bersamaan pada detik ke 7 setelah rangkaian mikrokontroler terpicu tegangan.

3. Alat bekerja dengan baik pada Baud Rate 115200 .

4. Kecepatan pengiriman SMS sangat tergantung pada kualitas layanan perusahaan penyedia jaringan GSM. Pemakaian jenis simcard dari produk yang sama akan mempunyai nilai tempuh SMS yang relatif. 
Jurnal IImu Teknik Elektro Komputer dan Informatika (JITEKI)

Vol. 2, No. 1, Juni 2016

\section{Referensi}

[1] Lukman, H., 2009. Sistem Pengaman Kendaraan Bermotor Menggunakan SMS Berbasis Mikrokontroler AVR ATMega8535. Yogyakarta : Universitas Negeri Yogyakarta.

[2] Teguh, W., 2011. Sistem Keamanan Rumah dengan Menggunakan Motion Dan SMS Gateway. Jawa Timur: Universitas Pembangunan Nasional "VETERAN".

[3] Febryana, S., 2010. Pembuatan Pototype System Pengaman Kendaraan Bermotor Berbasis Mikrokontroller dan SMS Gateway. Jawa Timur: Prodi Teknik Informatika Universitas Pembangunan Nasional "VETERAN".

[4] Rizki E., 2012. Media Pembelajaran Mikrokontroler AVR. Yogyakarta : Universitas Negeri Yogyakarta

[5] Bejo, A. 2008. Rahasia Kemudahan Bahasa C dalam Mikrokontroler ATMega8535. Yogyakarta: Graha IImu.

[6] Cooper, W. D. 1985. Intrumentasi Elektronika Dan Teknik Pengukuran. Jakarta: Erlangga.

[7] Jacob, J., M., 1989. Industrial Control Electronics applications And Design. United States of America: Prentice-Hall, Inc.

[8] Bishop, O, 2002, Dasar-Dasar Elektronika (Seri Profesi Elektronika) : Penerbit Erlangga.

[9] Firdausy, K. 2008. Modul Praktek Bahasa Pemrograman. Yogyakarta: Teknik Elektro, Universitas Ahmad Dahlan

[10] Innovative Electronics (2003). Bring Tecnology To Your Hand. Diperoleh dari :

[11] Winoto, A. 2008. Mikrokontroler AVR Atmega8/ 16/32/8535 dan Pemrogramannya dengan Bahasa C pada WinAVR. Bandung: Informatika. 